\title{
DESENVOLVIMENTO DE NANOPARTÍCULAS DE PLGA PARA ENCASULAÇÃO DE PROTEÍNAS UTILIZANDO DIFERENTES VARIÁVEIS
}

\author{
M. C. MORAIS ${ }^{1}$; A.E.M. BRITO'; ${ }^{1}$ A.C. APOLINARIO²; M.Y. F.A. REIS ${ }^{3}$; A. \\ PESSOA Jr² ${ }^{2}$ J.A. SILVA ${ }^{3}$
}

${ }^{1}$ Programa de Pós-Graduação em Desenvolvimento e Inovação Tecnológica em Medicamentos (DITM), Universidade Federal da Paraíba (UFPB), João Pessoa, PB, Brasil.

${ }^{2}$ Programa de Pós-Graduação em Tecnologia Bioquímico-Farmacêutica, Faculdade de Ciências Farmacêuticas, Universidade de São Paulo (USP), São Paulo, SP, Brasil.

${ }^{3}$ Programa de Pós-Graduação em Ciências Farmacêuticas (PPGCF), Universidade Estadual da Paraíba (UEPB), Campina Grande, PB, Brasil.

E-mail: mayaracastrodemorais@gmail.com

RESUMO: Desenvolver sistemas de liberação para proteinas requer um sistema de encapsulação e liberação diferente daqueles comumente empregados para fármacos sintéticos, em razão, sobretudo, do seu tamanho. Nanopartículas elaboradas a partir de polímeros são consideradas um sistema promissor para o carreamento de proteínas para sitios especificos. Estas podem ser formuladas a partir de polímeros de origem natural ou sintética, desde que os mesmos sejam biocompativeis e biodegradáveis. Algumas variáveis, tais como concentração do tensoativo e tempo de homogeneização interferem diretamente na elaboração das mesmas. As nanopartículas foram obtidas pelo método de dupla emulsificação, onde foi usado o polímero poli (ácido lático-co-glicólico) com proporção (50:50) e tamanho de cadeia 24,000-38,000 Da. Após a obtenção, foram analisadas pela técnica de espalhamento de luz dinâmico e microscopia eletrônica de transmissão (MET). Os resultados mostraram que o sistema D apresentou índice de polidispersão (IPD) com 0,143, com tamanho de partícula de 389,5 $\mathrm{nm}$. Por serem compativeis com dados da literatura pode-se sugerir que é possivel o encapsulamento de proteínas a partir do sistema desenvolvido.

Palavras-chave: Proteínas, nanopartículas, PLGA, dupla emulsificação

ABSTRACT: Developing release systems for proteins requires a different encapsulation and release system than those commonly employed for synthetic drugs, mainly because of their size. Nanoparticles made from polymers are considered a promising system for carrying proteins to specific sites. These may be formulated from polymers of natural or synthetic origin, provided they are biocompatible and biodegradable. Some variables, such as surfactant concentration and homogenization time, interfere directly in the preparation of the same. The nanoparticles were obtained by the double emulsification method, where the poly (lactic-co-glycolic acid) polymer with proportion (50:50) and chain size 24,000-38,000 Da was used. After obtaining, they were analyzed by the technique of spreading of dynamic light and transmission electron microscopy (MET). The results showed that the D system presented polydispersion index (IPD) with 0.143, with a particle size of $389.5 \mathrm{~nm}$. Because they are compatible with literature data, it may be suggested that encapsulation of proteins from the developed system is possible. 


\section{INTRODUÇÃO}

Desenvolver sistemas de liberação para proteínas requer um sistema de encapsulação e liberação diferente daqueles comumente empregados para fármacos sintéticos, em razão, sobretudo, do maior tamanho e da hidrofilia destas. Nanopartículas elaboradas a partir de polímeros são consideradas um sistema promissor para o carreamento de proteínas para sítios específicos. Para sua produção, o copolímero PLGA é amplamente utilizado e aceito pela indústria farmacêutica por ser biodegradável e biocompatível. Estas são obtidas através de alguns métodos, a exemplo o método de dupla emulsificação, o qual é adequado para moléculas hidrofílicas como as proteínas. (DANHIER et al., 2012). A principal abordagem para caracterização destas formas farmacêuticas envolve as análises de tamanho de partícula por meio da análise do raio hidrodinâmico através do espalhamento de luz dinâmico e a microscopia eletrônica de transmissão (BOOTZ et al., 2004).

Nesse estudo, foi feita a análise do tamanho de partícula, índice de polidispersão e MET das nanopartículas de PLGA, levando em consideração algumas variáveis: concentração do tensoativo e tempo de homogeneização. O objetivo dos testes foi obter o sistema mais viável e adequado para posterior encapsulação de proteínas.

\section{MATERIAIS E MÉTODOS}

As propriedades físico-químicas das nanopartículas podem ser comprometidas por variáveis usadas na elaboração das mesmas. Dentre elas estão: concentração do tensoativo e tempo de homogeneização. Estas variáveis foram estudadas neste trabalho com a finalidade de se chegar a um sistema ideal, mantendo todas as outras constantes durante a elaboração das nanopartículas.

\subsection{Nanopartículas}

\subsubsection{Polímero}

Polímero de PLGA com proporção de 50:50 (Ácido lático (PLA): Ácido glicólico (PGA)) e peso molecular de 24,000-38,000 Da.

\subsubsection{Preparação das Nanopartículas}

Foram preparadas soluções de PVA nas concentrações de $0,5 \%$ e $1 \%$. Para $1^{\circ}$ emulsão, pesou-se $0,05 \mathrm{~g}$ de PLGA, solubilizou-se em 2,5 $\mathrm{mL}$ de clorofórmio e em seguida foi adicionado a essa mistura $250 \mu \mathrm{L}$ de tampão PBS 7,4, a solução obtida foi submetida a três ciclos de sonicação com sonda ultrasson com potência de $50 \%$ em banho de gelo por 30 ou 60 segundos. Para obter a $2^{\circ}$ emulsão, a $1^{\circ}$ emulsão foi vertida em 10 $\mathrm{mL}$ da solução de PVA nas respectivas concentrações e levada novamente para sonicação. A emulsão formada foi levada para evaporação do solvente (24 horas). Em seguida, os sistemas foram centrifugados, lavados com solução tampão PBS 7,4 e ressuspendidos para posterior caracterização. 


\subsection{Caracterização das nanopartículas}

\subsubsection{Espalhamento de luz dinâmico}

A análise de espalhamento de luz dinâmico, que permite inferir sobre o raio hidrodinâmico dos sistemas de nanopartículas (do inglês Dynamic light scattering (DLS)) foi feita na concentração de $1 \mathrm{mg} \cdot \mathrm{mL}^{-1}$ bem como das amostras diluídas no equipamento Zetasizer (Mlavern Instruments).

\subsubsection{Microscopia eletrônica de transmissão (MET)}

As imagens do TEM das nanopartculas foram obtidas do microscópio eletrônico de transmissão (modelo Tecnai Spirit Biotwin G2, FEI, Oregon, Estados Unidos) operando a uma tensão de aceleração de $200 \mathrm{kV}$. Alíquotas de $5 \mu \mathrm{L}$ de cada amostra das NPs foram diluídas em água destilada e depositadas sobre placas de cobre.

\section{RESULTADOS E DISCUSSÃO}

Tabela 1: Valores de tamanho de partícula por intensidade e número e índice de polidispersão (IPD) para nanopartículas preparadas com PLGA $(24,000-38,000 \mathrm{Da})$.

\begin{tabular}{|c|c|c|c|c|c|}
\hline $\begin{array}{c}\text { Nanopartículas } \\
\text { (PLGA) }\end{array}$ & $\begin{array}{c}\text { Concentração de } \\
\text { álcool polivinílico } \\
(\%)\end{array}$ & $\begin{array}{l}\text { Técnica de } \\
\text { obtenção }\end{array}$ & $\begin{array}{c}\text { Tempo de } \\
\text { homogeneização }\end{array}$ & $\begin{array}{c}\text { Diâmetro } \\
\text { hidrodinâmico por } \\
\text { intensidade }(\mathrm{nm})\end{array}$ & $\begin{array}{c}\text { Índice de } \\
\text { Polidispersão } \\
\text { (IPD) }\end{array}$ \\
\hline Sistema A & 0,5 & $\begin{array}{c}\text { Cavitação } \\
\text { com sonda de } \\
\text { ultrassom }\end{array}$ & $30 \mathrm{~s}$ & \multicolumn{2}{|c|}{ Separação de fases } \\
\hline Sistema B & 0,5 & $\begin{array}{l}\text { Cavitação } \\
\text { com sonda de } \\
\text { ultrassom }\end{array}$ & $60 \mathrm{~s}$ & \multicolumn{2}{|c|}{ Separação de fases } \\
\hline Sistema C & 1,0 & $\begin{array}{l}\text { Cavitação } \\
\text { com sonda de } \\
\text { ultrassom }\end{array}$ & $30 \mathrm{~s}$ & \multicolumn{2}{|c|}{ Separação de fases } \\
\hline Sistema D & 1,0 & $\begin{array}{l}\text { Cavitação } \\
\text { com sonda de } \\
\text { ultrassom }\end{array}$ & $60 \mathrm{~s}$ & $389,5(100 \%)$ & 0,143 \\
\hline
\end{tabular}

Os sistemas A, B e C apresentaram logo após a preparação, separação de fases, enquanto que o sistema $\mathrm{D}$ mostrou-se homogêneo após sua elaboração, sem sinais de coalescência. De acordo com Sharma et al., (2016), a concentração de tensoativo usada para a preparação das nanoparticulas é de fundamental importância, porque em concentrações adequadas pode evitar a coalescência do sistema formado. Após esses resultados, o sistema obtido foi caracterizado.

Pode-se observar pela figura 1 que o resultado da análise de espalhamento de luz dinâmico aponta para nanopartículas com 383,9 $\pm 13,91$ e um baixo grau de polidispersão, com IPD de 0,143 $\pm 0,03$. A literatura relata tamanhos próximos a $400 \mathrm{~nm}$, o que está de acordo com os resultados encontrados neste estudo (KULLKAMP, et al., 2009). O IPD do sistema analisado de 0,143 está abaixo do índice $(<0,3)$ preconizado e de acordo com a literatura, confirmando homogeneidade na distribuição das partículas (Courant, et al., 2009). 
Figura 1: Tamanho de partícula por intensidade

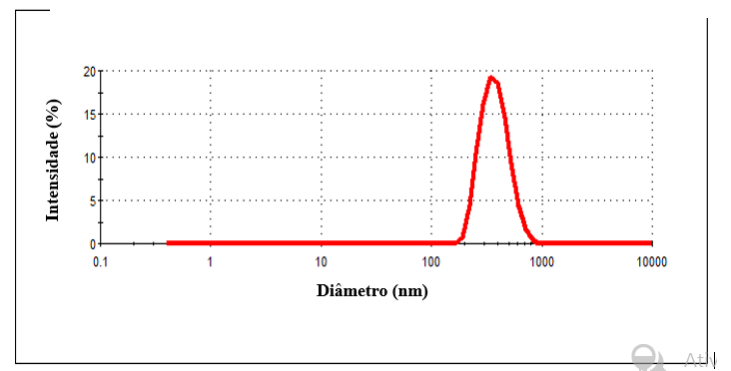

Figura 2: Tamanho de partícula por MET

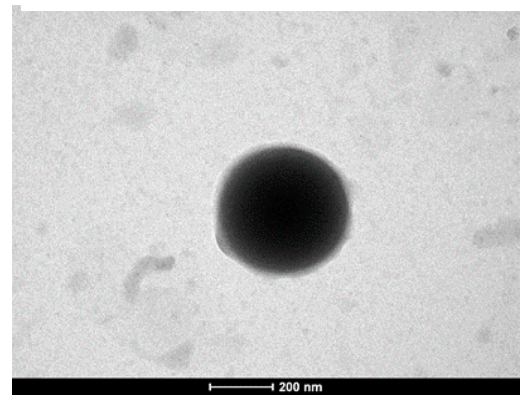

As nanoparticulas foram caracterizadas por TEM e se apresentaram dispersas, sem sinais de agregação, como está ilustrado na Figura 2. O tamanho das partículas foi medido com auxílio do programa Image $\mathrm{J}$ e foram consistentes com os resultados obtidos a partir do DLS. Foi possível observar a similaridade das NPs com outras NPs de PLGA relatadas na literatura (Rodríguez-Nogales et al., 2016).

\section{CONCLUSÃO}

Pode-se concluir que foi possível a obtenção de nanoparticulas de PLGA pelo método da dupla emulsificação, confirmados pela técnica de espalhamento de luz dinâmica e microscopia eletrônica de varredura e compatíveis com dados encontrados na literatura, ao mesmo tempo que pode-se sugerir a encapsulação de proteínas pelo sistema desenvolvido.

\section{REFERÊNCIAS}

BOOTZ, A. et al. Comparison of scanning electron microscopy, dynamic light scattering and analytical ultracentrifugation for the sizing of poly (butyl cyanoacrylate) nanoparticles. European Journal of Pharmaceutics and Biopharmaceutics, v. 57, p. 369-375, 2004.

COURANT, T. et al. Development and physicochemical characterization of copper complexes-loaded PLGA nanoparticles. International Journal of Pharmaceutical, v. 379(2), p.226-34, 2009.

DANHIER, F. et al. PLGA-based nanoparticles: An overview of biomedical applications. Journal of Controlled Release, v. 161, n. 2, p. 505-522, 2012.

KÜLKAMP, I. C. et al. Aceitação de práticas não-convencionais em saúde por estudantes de medicina da Universidade do Sul de Santa Catarina. Revista Brasileira de Educação Médica, v. 31(3), p. 229-235, 2007.

SHARMA, N. et al. Effect of process and formulation variables on the preparation of parenteral paclitaxelloaded biodegradable polymeric nanoparticles: A co-surfactant study. Asian Jornal of Pharmaceutical Sciences, v.11, p.404-416, 2016.

RODRÍGUEZ-NOGALES, C. et al. Development and characterization of polo-like kinase 2 loaded nanoparticles-A novel strategy for (serine-129) phosphorylation of alphasynuclein. International Journal of Pharmaceutics, v. 514(1), p.142-149, 2016.

\section{AGRADECIMENTOS}

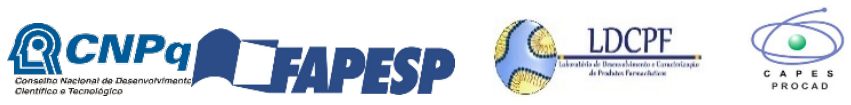

